\title{
Exploring Nursing Student Self-esteem and its Relationship to Clinical Competence Development: Protocol for A Multiphase Convergent Mixed Methods Study
}

\author{
Jacinthe Dancot $^{* 1}$, Benoît Pétré ${ }^{1}$, Pascal Detroz ${ }^{2}$, Rémi Gagnayre ${ }^{3}$, Nadia Dardenne ${ }^{1}$, Anne-Françoise Donneau ${ }^{1}$ and \\ Michèle Guillaume ${ }^{1}$ \\ ${ }^{1}$ Public Health Sciences Department, University of Liege, Liege, Belgium \\ ${ }^{2}$ Interfaculty Research Unit in Didactics and Teacher Training, University of Liege, Belgium \\ ${ }^{3}$ Health Education and Practices Laboratory, Department of Health Sciences Education, University Paris 13-Sorbonne, France
}

\begin{abstract}
Background: Self-esteem affects nursing students' well-being and may impact their competence development. Nursing students appear to be at risk for low self-esteem, and their training may negatively impact that selfesteem. The existing research, with its controversies, methodological issues, and gaps, has failed to fully portray or explain this phenomenon. Mruk's two-dimensional model of self-esteem offers an operative theoretical framework based on self-competence and self-liking. The model describes the nature of 'selfesteem moments' in which self-esteem changes. The aim of this study is to answer the question: "How does undergraduate nursing education influence students' self-esteem, specifically regarding the development of their clinical competence?"
\end{abstract}

Methods: A longitudinal design is needed to describe changes during undergraduate nursing education. A mixed methods study is required to measure and explain those changes, with a convergent, multiphase design. A nursing student cohort is created by accidental sampling in four Belgian high schools and followed for three years. Quantitative data including sociodemographic data, self-esteem (as measured by the Rosenberg scale and the Tafarodi \& Swann scale), self-efficacy, and state anxiety (Spielberger scale) are collected each year. These data will be used to describe changes in self-esteem level and profile during nursing education. Multivariate analysis is used to identify correlated factors. Qualitative data are collected each year via semi-structured interviews with a cohort created by purposive sampling; content analysis is performed on that data(hermeneutic phenomenology) to identify themes using repetitions, similarities and differences, indigenous categories, and theory-related material. The quantitative and qualitative data are then combined into a meta-matrix.

Discussion: The challenges encountered during study designing involved following the cohort while minimizing missing data, validating the French translation of a self-esteem scale using nursing students, and dealing with a large volume of data, especially when assembling it into a meta-matrix. The aim of the study is to help educational institutions tackle the self-esteem issue. Future studies might also compare nursing students to other students, explore the situation of dropouts, and evaluate self-esteem-related pedagogical devices.

\section{Publication History:}

Received: May 01, 2020

Accepted: June 08, 2020

Published: June 10, 2020

\section{Keywords:}

Integration, Meta-matrix, Mruk, Self-value, Selfcompetence, Triangulation

\section{Abbreviations:}

RSES-r: Rosenberg Self-Esteem Scale, revised version SCLS-r: Self-Liking/SelfCompetence Scale, revised version

STAI-Y-A: State-Trait Anxiety Inventory, Form Y, Form A

\section{Trial Registration:}

This non-interventional study was approved by the ethics committee (Comité d'Éthique Hospitalo-Facultaire Universitaire de Liège (707)) and assigned reference no. 2017/233.

\section{Background}

Competent nursing is essential to patient safety and quality of care. The competence of nursing students and novice nurses is often called into question [1-30]. Nursing students see themselves [27], and are seen by professionals [3], as lacking preparation and autonomy. For example, Flemish Belgian nursing students in their final year of nursing school felt competent in only 9 out of 26 nursing skills [27]. In this paper, clinical competence is used as a global indicator of the various skills that nurses need to develop. While most studies finding a lack of competence advocate for better education and more support/ supervision during clinical practice [1,2,6-9,11-13,15-18,20,24$26,28,30]$, what is most needed to optimise nursing education seems to be a comprehensive examination of the issue.

There may be foundational elements common to the development of all of the skills required of nursing students. Self-esteem-defined as the emotional response to perceived self-value and to the disparity between the actual self and the ideal self [31,32] -might be such an element, as it is thought to affect nursing students' professional behavior $[33,34]$ and their commitment to academic achievement [35]. In turn, a sense of self-competence reinforces self-esteem [36-38], leading to a kind of feedback loop whose dynamics are not well understood.

In addition, there is growing interest in nursing student well-being, and self-esteem is correlated with both well-being and mental health $[36,39]$. Nursing students appear to be at risk of low self-esteem, and/ or their self-esteem may decline during their training. The influence of nursing education on student self-esteem is multifactorial and unclear.

*Corresponding Author: Jacinthe Dancot, Public Health Sciences DepartmentQuartier Hôpital, Avenue Hippocrate, 13, Bâtiment B23, 4000 Liège, Belgium, Tel: +32 476681 812; E-mail: jacinthe.dancot@uliege.be

Citation: Dancot J, Pétré B, Detroz P, Gagnayre R, Dardenne N, et al. (2020) Exploring Nursing Student Self-esteem and its Relationship to Clinical Competence Development: Protocol for A Multiphase Convergent Mixed Methods Study. Int Nurs Clin Pract 7: 324. doi: https://doi.org/10.15344/2394-4978/2020/324

Copyright: (c) 2020 Dancot et al. This is an open-access article distributed under the terms of the Creative Commons Attribution License, which permits unrestricted use, distribution, and reproduction in any medium, provided the original author and source are credited. 
Citation: Dancot J, Pétré B, Detroz P, Gagnayre R, Dardenne N, et al. (2020) Exploring Nursing Student Self-esteem and its Relationship to Clinical Competence Development: Protocol for A Multiphase Convergent Mixed Methods Study. Int J Nurs Clin Pract 7: 324. doi: https://doi.org/10.15344/2394-4978/2020/324

Page 2 of 12

The purpose of this paper is to present, support, and discuss a study protocol whose aim is to explore self-esteem in Belgian nursing students and its impact on clinical competence, as perceived by the students themselves and evaluated objectively by their grades during clinical training. We begin by discussing the theoretical foundations of the self-esteem concept and how these determined our methodological choices. We propose a robust, original design for studying nursing student self-esteem longitudinally using a mixed methods approach. We then discuss the protocol in terms of the originality of its subject and methods and the strengths and limitations of the latter. We discuss possible implications of the study, such as theoretical controversies, and the methodological challenges we encountered. We hope that this protocol inspires others to fill in the gaps in our knowledge on this subject.

\section{Self-esteem in nursing students}

Many studies have looked at nursing student self-esteem, illustrating the importance of this issue. The results are contradictory, and should be interpreted with caution due to methodological limitations and difficulties in comparing studies. These are summarised in Table 1.

\begin{tabular}{|l|}
\hline Different definitions of and/or approaches to self-esteem \\
\hline Lack of a theoretical framework in some studies \\
\hline Different self-esteem assessment scales \\
\hline Arbitrary (and differing) thresholds applied to the results of the scales \\
\hline $\begin{array}{l}\text { Inconsistencies between the theoretical framework and the scale } \\
\text { used in some studies }\end{array}$ \\
\hline Different study populations [40] \\
\hline Different measurement schedules [8,41,42] \\
\hline Design often cross-sectional or post-interventional \\
\hline Losses to follow-up due to attrition [43] \\
\hline Impact of the vocational character of the training [44] \\
\hline $\begin{array}{l}\text { Few explanations of the phenomenon (process and reasons for } \\
\text { changes in self-esteem, or interaction mechanisms) }\end{array}$ \\
\hline
\end{tabular}

Table 1: Why is it so difficult to draw a conclusion on nursing student self-esteem?

Self-esteem is usually assessed as medium to low by nursing students, as compared with other students (e.g., psychology students [45]) and the general population $[44,46,47]$, or by intragroup comparison [4853]. Moreover, self-esteem appears to decline during undergraduate nursing education (preregistration courses) [33,34,54-62]. There are, however, conflicting results about this $[8,40,42,44,63-72]$. The reasons why nursing student self-esteem might be low or decline during their training have yet to be fully explored. Along with a decline in selfesteem, there is an increase in contingent self-esteem (a vulnerability marker) during nursing education [46]; a decline in assertiveness [67]; and an increase in stress by the end of the course of study [59].

Many interrelated factors may impact nursing student self-esteem or be correlated with it. During undergraduate nursing education, instructor feedback - both positive and negative - has a large impact on self-confidence [73]. Clinical training periods also have a significant impact, as self-esteem is influenced by the professionalisation and socialisation process [74]. Self-esteem becomes fragmented (simultaneously high -due to being a medical professional and someone with power over others - and low -due to being part of an oppressed profession), and students lose the ability to become thenurse they would like to be and feel unwelcome, anxious, depressed, and sad $[33,34,75]$. Nursing students first identify the nursing role and then begin to identify more closely with professional nurses (rather than instructors) [73]. Students integrate the social norms they encounter during clinical training (including bullying) [33,34,75]. Clinical training is more conducive to learning when students are included in the nursing team [74]. Self-esteem and a sense of belonging during clinical training (which are positively correlated) have an impact on self-directed learning [76].

According to various studies, self-esteem is also correlated with a number of contextual factors, as shown in Table 2. "Pressure factors" are counterbalanced by "protective factors" [77]. Table 2 shows the factors that are positively and negatively correlated with nursing student self-esteem, based on a variety of studies. These can be used to identify the most important factors and to understand the complexity of the system. While numerous factors in this complex system have been identified, there has been little exploration or explanation of their interconnections, causes, and reciprocal effects.

\begin{tabular}{|l|l|}
\hline $\begin{array}{l}\text { Positive correlation with nursing } \\
\text { student self-esteem }\end{array}$ & $\begin{array}{l}\text { Negative correlation with } \\
\text { nursing student self-esteem }\end{array}$ \\
\hline $\begin{array}{l}\text { Relational abilities: assertiveness } \\
\text { [41,78], ability to communicate [56] }\end{array}$ & $\begin{array}{l}\text { Mental health indicators: } \\
\text { despair or depression } \\
\text { [47,59,64,84,85,87,88], } \\
\text { mental illness [87,89], } \\
\text { stress [43,58,70,82], state } \\
\text { anxiety [43,53,59,63] }\end{array}$ \\
\hline $\begin{array}{l}\text { Feeling management: emotional } \\
\text { intelligence [78], effective coping } \\
\text { [57,70,79-82] and effective feeling } \\
\text { management strategies [83], anger } \\
\text { management [64,68] }\end{array}$ & $\begin{array}{l}\text { Relational characteristics: } \\
\text { negative relationships [89], } \\
\text { aggressive behaviours [90] }\end{array}$ \\
\hline $\begin{array}{l}\text { Self-evaluation: self-perception, } \\
\text { ability to self-assess, self-efficacy [40] }\end{array}$ & $\begin{array}{l}\text { Personal characteristics: } \\
\text { [outh [46], female gender }\end{array}$ \\
\hline $\begin{array}{l}\text { Personal characteristics: religious } \\
\text { beliefs [84,85], familial cohesion, } \\
\text { social and emotional support } \\
\text { [80,82,83], health status in general } \\
\text { [82] or good mental health [63,81] }\end{array}$ & $\begin{array}{l}\text { Attrition, via self-efficacy } \\
\text { [91] }\end{array}$ \\
\hline $\begin{array}{l}\text { Learning process and outcomes: } \\
\text { critical thinking [53], success } \\
\text { [63], persistence, goal-oriented } \\
\text { competitiveness [86] }\end{array}$ & \\
\hline $\begin{array}{l}\text { Professional characteristics: } \\
\text { professional identity development, } \\
\text { professional perspectives [65], values } \\
\text { internalisation [8,69], professional } \\
\text { competence [42] or perception of } \\
\text { competence [63,66] }\end{array}$ & \\
\hline
\end{tabular}

Table 2: Factors correlated with nursing student self-esteem.

Specifically, anxiety and stress are negatively correlated with self-esteem in many studies, and are high in nursing students $[43,49,51,53,58,59,61,63,70,76,79,82,84,85,92-94]$. Undergraduate nursing education has a number of important stressors, including clinical training and the final dissertation [68]. The biggest stressors are understaffing, dealing with death and the dying process, excessive workload, and conflicts with physicians $[43,95]$.

\section{Mruk's two-dimensional conception of self-esteem}

Numerous authors have conceptualised self-esteem using a unidimensional approach based on competence, like James and 
Citation: Dancot J, Pétré B, Detroz P, Gagnayre R, Dardenne N, et al. (2020) Exploring Nursing Student Self-esteem and its Relationship to Clinical Competence Development: Protocol for A Multiphase Convergent Mixed Methods Study. Int J Nurs Clin Pract 7: 324. doi: https://doi.org/10.15344/2394-4978/2020/324

White [36], or worthiness, like Rosenberg [39] and Leary [96]; a twodimensional approach based on both, like Mruk [36] and Tafarodi \& Swann [37,38]; or a multidimensional (academic, familial, and physical self-esteem, etc.) approach, like Coopersmith, Harper and Shavelson $[32,35,96]$. Use of existing assessment scales must be consistent with the theoretical approach taken.

Conceptualising self-esteem using a two-factor approach based on competence and worthiness incorporates the cognitive and affective dimensions and constitutes a satisfactory operational definition [97], surmounting the debate in the literature about self-esteem and explaining its contradictory results [36]. This conceptualisation focuses on dimensions possibly impacted by the academic experience and explains some of the contradictory results from self-esteem studies that take a unidimensional approach [36]. Moreover, a twodimensional scale does exist [38].

Mruk [36] uses this approach to suggest an existentially-based definition of self-esteem: "Self-esteem is the lived status of one's competence at dealing with the challenges of living in a worthy way over time". The term status refers to something reasonably stable, yet liable to change under certain conditions. The lived quality expresses the fact that self-esteem is experienced. Competence refers to the possession of physical, cognitive and social abilities, but also to a feeling of selfefficacy in dealing with situations. Worthiness concerns the quality of actions taken in situations and their virtuousness, i.e., whether or not they are considered as just and right. Time is important because selfesteem must be managed over a lifetime.

As illustrated in Figure 1, Mruk [36] shows how competence and worthiness interact by displaying those variables along two orthogonal axes creating four quadrants, each quadrant representing one type of self-esteem: high self-esteem, defensive self-esteem based on achievement, defensive self-esteem based on acceptance, and low self-esteem. The majority of the general population has a medium high self-esteem.

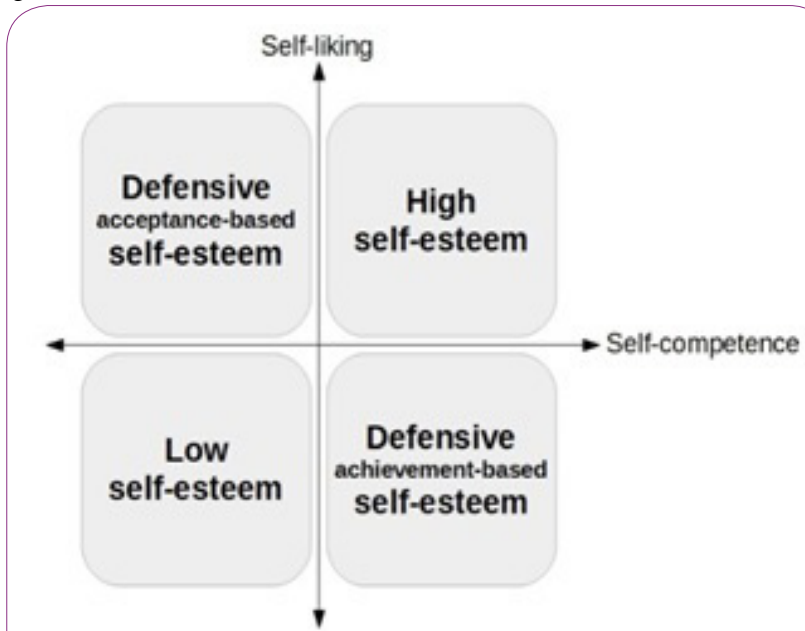

Figure 1: Mruk's two-dimensional model of self-esteem (Adapted from Mruk [36] and used with his permission).

The competence level is influenced by success/failure experiences, and the worthiness level by acceptance/rejection experiences. According to Mruk [36], while self-esteem is quite stable in older teens and adults, people sometimes experience "self-esteem moments" [36] that affect their self-esteem when facing special challenges involving assessment of their competence and their inclusion in new social groups. Self-esteem moments are "times when an individual is acutely aware of his or her self-esteem as a result of having to face various challenges of living, such as overcoming a fear, going beyond a personal limitation, doing the right thing when it is the most difficult alternative, and so forth." [98]. Self-esteem in general, and self-esteem moments in particular, concern domains of importance to the individual.

What Mruk is conceptualising is sometimes called "explicit self-esteem," referring to its conscious dimension. Measuring (explicit) self-esteem presents some methodological challenges, as self-assessment scales are self-reported tools, and thus subject to ceiling and social desirability effects that can lead to false positives. Moreover, those scales are often transparent and easily manipulated by the participant. Few instruments can detect cognitive rigidity, defensiveness, narcissism, antisocial tendencies, or unstable, frail, or defensive self-esteem [36].

For that reason, it is useful to focus on a less conscious phenomenon as well. In contrast with explicit self-esteem, implicit self-esteem is defined as "an automatic, over learned, and unconscious evaluation of the self that guides spontaneous reactions to self-relevant stimuli" and reflects experiential, rather than cognitive, beliefs [99]. It is measured indirectly, for example by the value people assign to self-related objects (the mere ownership effect). The incongruence of explicit and implicit measures of self-esteem can lead to a conclusion of defensiveness or frailty.

\section{Research question and aim of the study}

Given (1) the complexity of the "self-esteem system", (2) its potential impact on clinical competence development, and (3) uncertainty regarding the conclusions from existing research, this study attempts to answer the question: "How does undergraduate nursing education affect students' self-esteem, specifically regarding the development of their clinical competence?" A longitudinal mixed methods study should help resolve some of the controversy and shed new light on the issue of competence deficiency, answering whether, how, and why self-esteem changes during nursing education, and whether, how, and why this is related to clinical competence development.

The aim of the study is to explore the interplay between self-esteem and clinical competence in nursing students, and how undergraduate nursing education impacts it. The specific aims are (1) to explore the correlation between self-esteem and clinical and academic performance, and the process of how they influence each other; (2) to predict self-esteem's effect on clinical and academic performance; and (3) to explore the impact of undergraduate nursing education specific events or facts, in particular - on student self-esteem.

\section{Methods/Design}

\section{Research paradigm and study design}

A pragmatic paradigm suits the above aims well, because collecting different types of data provides a better understanding of the phenomenon being studied [100] and because the study aims require a variety of methods. The pragmatic paradigm places the emphasis on the meaning and consequences of events in a social situation, focusing on human experience [101], and allows an interpretation of the notions being explored based on their practical consequences [102], which is the aim of the study. The use of different types of data is also consistent with Mruk's recommendation [36] to explore 
Citation: Dancot J, Pétré B, Detroz P, Gagnayre R, Dardenne N, et al. (2020) Exploring Nursing Student Self-esteem and its Relationship to Clinical Competence Development: Protocol for A Multiphase Convergent Mixed Methods Study. Int J Nurs Clin Pract 7: 324. doi: https://doi.org/10.15344/2394-4978/2020/324

Page 4 of 12

self-esteem using an integrative description, including a qualitative phenomenological approach (i.e. attempting to understand lived experiences among people who have a common experience [103]) and integrating quantitative results to see whether the description that emerges from the qualitative approach can be used to explain them.

The longitudinal design makes it possible to observe changes in the phenomenon being studied and identify relationships [100]. It is important to describe the impact of the educational process - which takes several years - on self-esteem.

This longitudinal mixed methods study involves collecting quantitative data about self-esteem and qualitative data about the process and lived experiences of students. It is a multiphase, convergent design [104] in which quantitative and qualitative data are collected simultaneously (but sequentially within each phase) and interpreted, first separately and then in a comparison matrix [105109]. The quantitative and qualitative data are weighted equally.

The design and tools used are consistent with Mruk's theoretical framework.

\section{Participants and sampling}

Only full-time bachelor's degree (four-year) programmes are considered in this study. In French-speaking Belgium, high school students are not required to complete a full academic year, but to earn the required number of credits. Students are free to choose which courses to take each year (within a framework of prerequisites); as the courses are not rigidly assigned to a specific academic year, students are not identified as being in a particular year.

Four high schools from 16 sites (11 institutions) offering a bachelor's in nursing were invited to participate using purposive sampling based on geographical, network, size, and institutional criteria allowing maximum diversity. All of the schools agreed to participate. About 1,000 students were estimated to be enrolled in the programme at the four institutions prior to data collection.

As shown in Figure 2, the student cohort is constructed by accidental sampling (attending class) for the quantitative part, and by purposive sampling for the qualitative part (based primarily on self-esteem profiles and maximizing sociodemographic and academic diversity).

To determine the number of participants needed for the quantitative part, we performed a power calculation based on the mean comparisons from two paired samples (change overtime). More precisely, the power calculation was based on a comparison of selfesteem level (a quantitative variable measured by the Rosenberg SelfEsteem Scale in previous studies) measured at two different times. By varying the effect size from 0.05 to 1.5 , we applied a two-tailed test for comparing the means from a paired sample using an uncertainty of 5\% and a power of $80 \%$. The calculation was done with $\mathrm{G}^{\star}$ Power software, version 3.1.9.2. Given the stability of self-esteem, we presume an effect size of 0.15 and need a sample size of 351 participants with complete data to get $80 \%$ power.

\section{Data collection}

As shown in Figure 2, at T0, a cohort is created in each institution with students just starting their education. Students attending year 1 and 2 classes are asked to participate. The questionnaire is completed during class time to maximise the number of participants; it takes about 15 minutes to complete. At the Principal Investigator's institution, the questionnaires are distributed by a research associate. The questionnaire includes a question asking participants if they would be willing to participate in the interviews.

Volunteers from the T0 quantitative cohort are selected to participate in the qualitative phase using sequential sampling [108]. Semi-structured interviews are conducted with student volunteers during classroom training periods, in order to avoid any fresh "sensitive situations" experienced during the clinical training periods. Appointments are made based on participant availability. A research associate conducts the interviews at the Principal Investigator's institution.

As shown in Figure 3, data collection is done each year for three years with the students enrolled in the cohort. The last set of quantitative data is collected from graduating students at the end of their programme (T3). It is impossible to meet with some of those students during class time because students often spend their entire final semester doing clinical training.

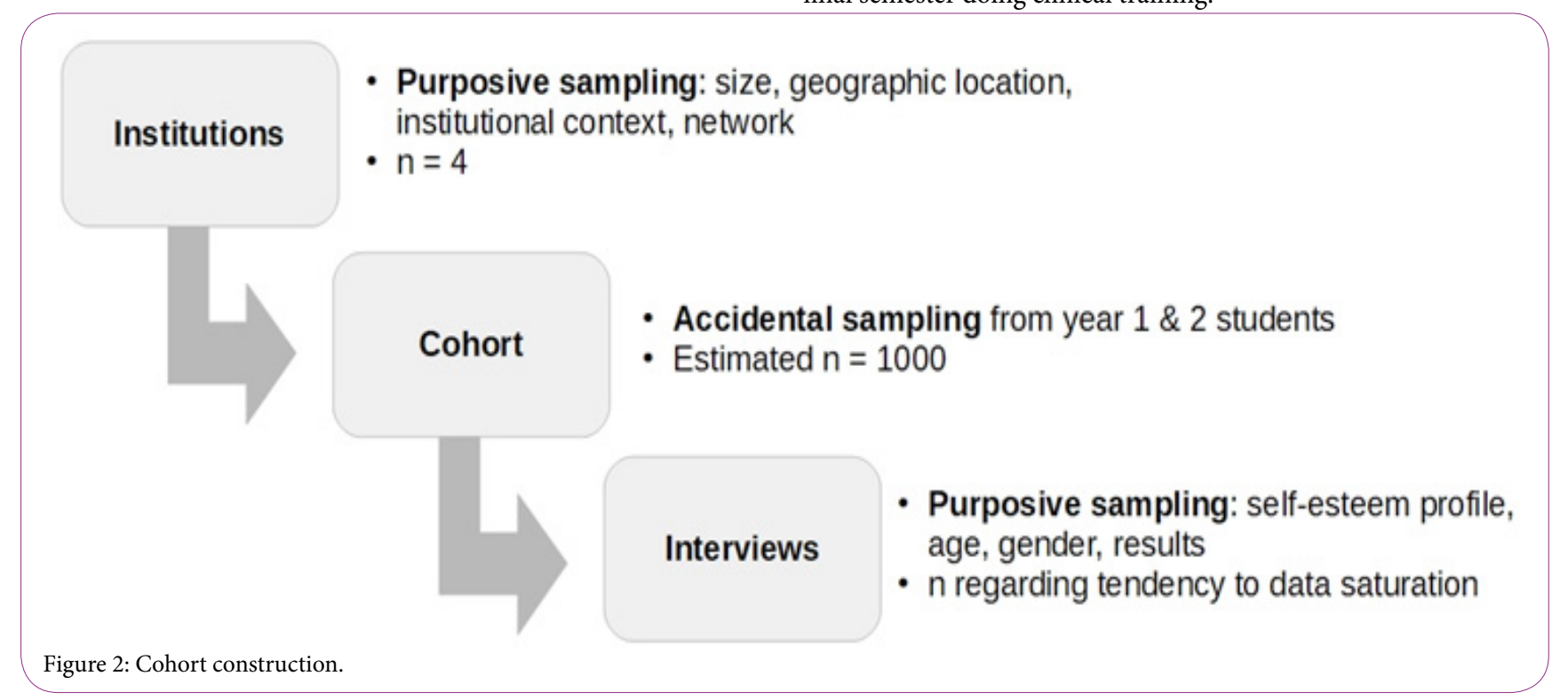


Citation: Dancot J, Pétré B, Detroz P, Gagnayre R, Dardenne N, et al. (2020) Exploring Nursing Student Self-esteem and its Relationship to Clinical Competence Development: Protocol for A Multiphase Convergent Mixed Methods Study. Int J Nurs Clin Pract 7: 324. doi: https://doi.org/10.15344/2394-4978/2020/324

Page 5 of 12

\section{Quantitative data collection}

The questionnaires are constructed the same way for each phase of the study; some sociodemographic questions are asked only at T0; these are identified with an asterisk ${ }^{*}$.

\section{Sociodemographic questions}

Information on gender ${ }^{\star}$, age ${ }^{*}$, level of secondary education* previous post-secondary education and results ${ }^{\star}$, previous ${ }^{\star}$ or current job or student job, and any spouses or children is collected.

Perceived social support (on a scale of 1 to 5 ) and intention to continue the programme (on a scale of 1 to 5 ) is also measured. The point of the intent-to-continue question is to assess the current degree of importance of the nursing programme to the student, because selfesteem is mostly influenced by events in areas considered important by the subject [36]

\section{Implicit self-esteem: Name-liking test}

The Name-Liking Test [110] is a quick, useful way to measure implicit global self-esteem; it involves answering the question "How much do you like your name?" on a nine-point scale (from $1=$ not at all to $9=$ very $m u$ ch). It is correlated with explicit self-esteem and with well-being indicators.

Measuring explicit self-esteem before implicit self-esteem tends to inflate the latter score [99], which is why the Name-Linking Test is done before the self-esteem scales, along with the sociodemographic questions.

\section{Self-efficacy}

The questionnaire explores three situations, namely the feeling of self-efficacy in terms of being able to (1) successfully complete nursing studies, (2) behave effectively during clinical training periods, and (3) be a good nurse. Each of these is measured on a scale of 1 (not at all able) to 5 (very able).

4. Self-esteem level and profile: Self-Liking/Self-Competence Scale, revised version (SLCS-r), translated into French

The Self-liking/Self-competence scale $[37,38]$ has been cited by Mruk [36] as a way to measure self-esteem in its two-dimensional conception. Its advantage over unidimensional scales is that it assesses both competence and worthiness. Its advantage over multidimensional scales is that it is briefer and assesses only dimensions that might be impacted by education (multidimensional scales also assess the familial self, physical self, etc.).

The revised version (SLCS-r) [38] consists of two eight-item subscales, with eight self-competence and eight self-liking indicators. Respondents indicate their degree of agreement $(1=$ strongly disagree to $5=$ strongly agree) with global statements reflecting low and high self-competence and self-liking. It has been tested for convergent and discriminant validity. It has been used with Korean nursing students [64].

As there was not yet a French version, the SLCS-r was translated using Hébert, Bravo \& Voyer's [111] recommendations for translating measurement scales into French. First, two independent translators translated the English version into French; an expert committee

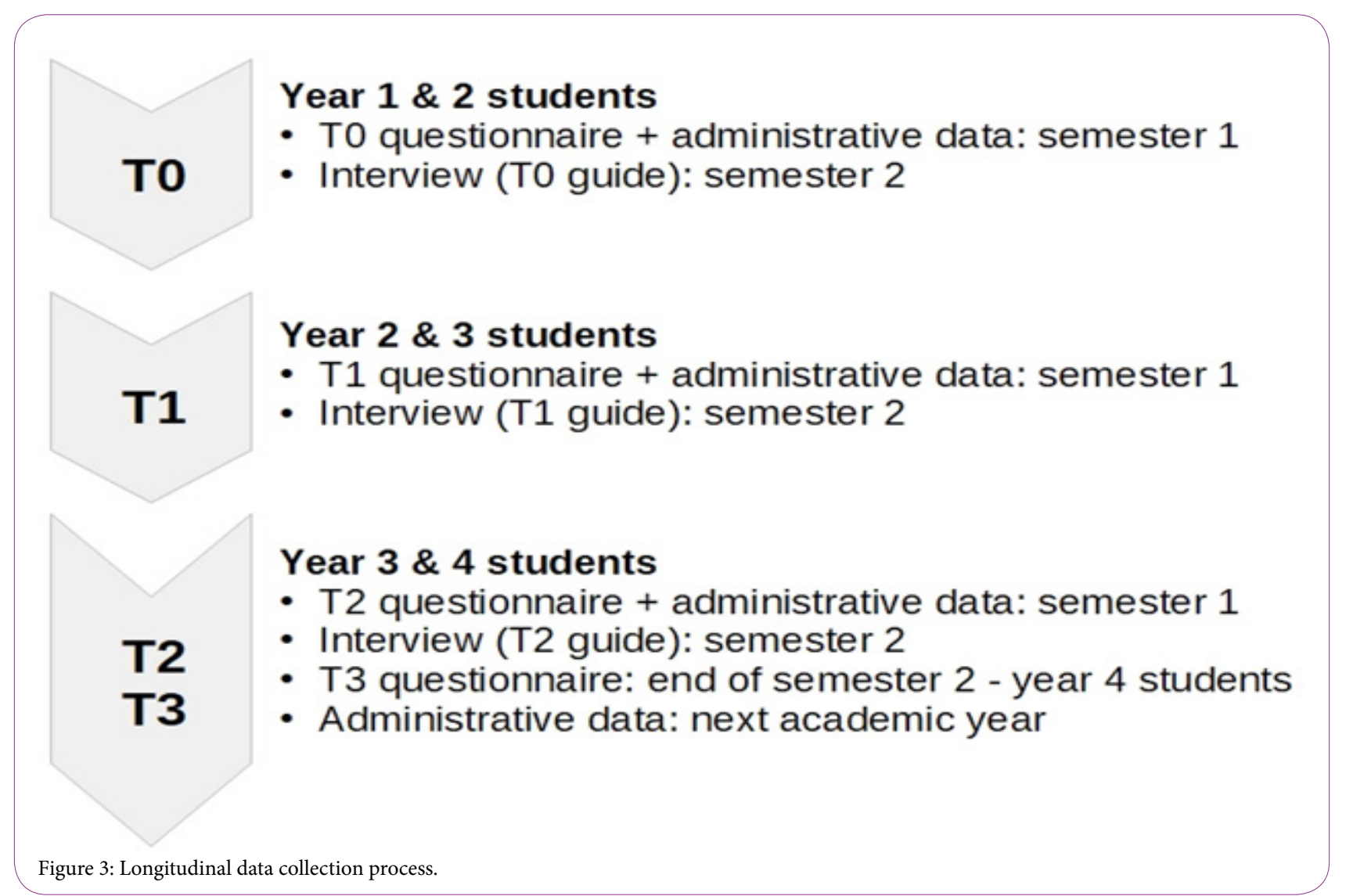


Citation: Dancot J, Pétré B, Detroz P, Gagnayre R, Dardenne N, et al. (2020) Exploring Nursing Student Self-esteem and its Relationship to Clinical Competence Development: Protocol for A Multiphase Convergent Mixed Methods Study. Int J Nurs Clin Pract 7: 324. doi: https://doi.org/10.15344/2394-4978/2020/324

Page 6 of 12

compared and revised their translations to produce a preliminary French version. That version was then back-translated by an English speaker, after which translators and experts compared the back translation to the original English version. The final French version was tested twice, three weeks apart, by 51 nursing students. The first time, the participants were asked for their opinion about the questionnaire's clarity. No changes were made after testing. As a number of translated self-esteem scales with similar questions had already been successfully tested for cultural correspondence, the translated questionnaire was not tested for that.

The SLCS-r produces a global self-esteem score. In accordance with Mruk's model [36], a self-esteem profile is obtained by comparing the self-liking and self-competence results.

5. Self-esteem level: revised Rosenberg Self-Esteem Scale (RSES-r), French version

The Rosenberg Self-Esteem Scale [39] is a measure of global selfesteem. It is a unidimensional scale [36,112-115], but is the scale used most widely to assess self-esteem, both in general and in studies on nursing students. It is used in this study to allow comparison with other studies.

First designed to measure self-esteem in teenagers, it has also been used in adults and the elderly $[113,116]$. The RSES-r contains 10 items, which are usually scored on a four-point scale ranging from 1 (strongly disagree) to 4 (strongly agree), with half of the items positively worded and half negatively worded.

A Canadian French version was translated and validated in a junior college student population [116], testing it for internal consistency, confirmatory factor analyses, construct validity and temporal stability.

\section{Anxiety-State level: STAI-Y-A scale, French version}

The French version of the Spielberger State-Trait Anxiety Inventory, Form Y (STAI-Y) contains two scales, one for measuring state anxiety (form A) and the other for measuring trait anxiety (form B) [117] Trait anxiety is a personality trait, which is stable over time, whereas state anxiety is temporary and linked to a specific stressful event. On the State-Anxiety form, the participant reports how he or she feels at the present moment on a 20 -item test including assertions scored on a four-point Likert scale $(1=$ not at all to $4=$ very much so $)$. Ten items have inverted scoring. Higher scores correspond to higher levels of anxiety. The scale has been tested for criterion validity, internal and external structure validity, fidelity, internal consistency, and intra- and inter-individual sensitivity to change.

Administrative data are obtained directly from the institution for each participant, i.e. the number of credits in the student's annual programme, the number of validated credits (academic performance), and clinical performance.

\section{Qualitative data collection}

The interviews are designed to provide a phenomenological understanding of the participant's lived experience. Each interview is planned to last about one hour and is recorded and transcribed in its entirety. It takes place in a single room with no one else present and no possible interruptions by members of the educational institution.
The guide for the T0 interview was constructed based on relevant theory and previous quantitative and qualitative research, and reviewed by experts in pedagogy, psychology, and sociology. The interview focuses on motivation (at the beginning and at the present moment), the ideal self, the actual self, and the source and effect of any gap between the two (which is depicted on a line). It then explores programme events (coursework, clinical training, grades, etc.) and external facts and feelings (e.g., social support). The participant is asked to describe each event, indicate its effect on his or her selfesteem, and indicate its effect on his or her learning or professional behaviour. It asks about the overall impact of the participant's training on his or herself-esteem and on that of students in general, about the participant's motivations in agreeing to participate, and about the interview experience itself.

The guide for the $\mathrm{T} 1$ and subsequent interviews begins with current motivation and then focuses on the previous line and the gap between the current ideal and actual self. Changes in and sources of that gap are explored, as are the effects on self-esteem and behaviour. As at T0, the interview ends by asking the participant about the overall impact of education on self-esteem, his or her motives for agreeing to participate, and his or her experience of the interview. Participants are also asked to give their high school advice concerning nursing student self-esteem.

\section{Analysis of the quantitative data}

All the data are entered in an Excel database and analysed using $\mathrm{R}$ software (version 3.4.2). Results are expressed as means \pm standard deviations (SDs) for quantitative variables and scores, while frequencies and proportions (\%) are used for categorical variables. The normality of the quantitative data is investigated graphically via a histogram and a quantile-quantile plot, as well as via a Shapiro-Wilk test. A logarithmic transformation is applied if needed. Mean values are compared by one-way analysis of variance (ANOVA) followed by multiple comparisons in case of several groups and by the Student t-test in case of two groups. Proportions are compared by the chisquared test for contingency tables. Nonparametric Kruskal-Wallis and Wilcoxon tests are also used for comparing samples from different groups when normality assumptions cannot be fulfilled. Correlation coefficients (classical or non-parametric Spearman) are calculated for measuring the association between two quantitative variables. Stepwise variable selection is used to retain the most discriminating variables. Actually, multiple regression and multinomial logistic regression are applied in two steps: (1) separately by domains, namely sociodemographic, academic and educational experience; and (2) globally for the variables identified as significant in step 1.The presence of missing data is investigated and, if needed, the appropriate approaches are considered. All tests are two-sided and the results are considered statistically significant at the $5 \%$ level $(\mathrm{p}<0.05)$. The Holm method is applied to correct all results for multiplicity.

At $\mathrm{T} 0$, the analyses are performed on the maximum available data. The aims of T0 analyses are:

1. To characterise the study population as a whole and by category based on educational stage: initial enrolment in nursing education, repeating first year students, intermediate year students;

2. To analyse and test associations between the variables of concern (self-esteem level and self-esteem profile) and the other parameters measured (sociodemographic, academic, and educational experience); 
3. To provide a baseline for studying changes in self-esteem (level and profile), state anxiety, intention-to-continue, and self-efficacy for the cohort as a whole and for each individual participant at subsequent times;

4. To predict academic and clinical performance based on selfesteem (level and profile);

5. To predict self-esteem (level and profile) based on other significant variables.

The aims of the analyses of subsequent times are:

1. To describe changes in self-esteem (level and profile), state anxiety, intent-to-continue, and self-efficacy for the cohort as a whole and for each individual participant;

2. To predict academic and clinical performance based on selfesteem (level and profile);

3. To predict self-esteem (level and profile) based on other significant variables.

The ultimate goal is to identify "high-risk profile students" in order to intervene pre-emptively.

\section{Analysis of the qualitative data}

After transcription, each T0 interview is read multiple times to identify themes from the interview guide and emerging themes. A general inductive approach [103] is used to analyse the qualitative data. The content analysis primarily uses repetitions, similarities and differences, indigenous categories, and theory-related material to identify themes and sub-themes [118].

Themes and subthemes are coded in NVivo 12 and validated by the research associate who conducts some of the interviews and by experts. Not knowing at T0 which categories will eventually emerge from the study, all of the segments of text are coded, and many segments are coded into more than one category, when links are possible (for example, a quote is coded as "contact with nursing team" and as "self-esteem" if a participant describes how a contact impacted his or her self-esteem). Refinement of the category system is left for later, when a global view is possible [103].

Saturation is achieved when the criteria described by Morse $[119,120]$ are met, i.e., the themes and subthemes give a comprehensive view of the topic and of all aspects of the phenomenon being explored there is enough replication in the data from a large and diverse sample; all of the data is given equal consideration, with variation valued over quantity; and "negative case" perspectives are explored and explained. That broad view of the phenomenon also ensures transferability $[100,121]$.

Data from each subtheme are condensed into a description containing structured data, verbatims, links to relevant theory and, at the conclusion, the (sub) theme's contribution to answering the research question [103].

The Principal Investigator listed her preconceptions about nursing student self-esteem beforehand. During the analysis process, discussions with experts help ensure reflexivity [121]. To avoid overinterpretation, data condensation should retain all of the relevant verbatims so that every reader is free to agree or disagree with how the data were classified and interpreted.
The themes and subthemes used for subsequent modelling are chosen [103] based on (1) the intensity (valence and duration) of their impact on student self-esteem or behaviour; (2) their frequency; (3) their ability to shed light on the research question; and (4) their link with theory, specifically Mruk's model [36]. Thus, there is an inductive analysis (themes and interpretation derived from raw data) and a deductive analysis (themes and interpretation based on theory); the use of both inductive and deductive analysis is common [103].

At the end of the study, qualitative part participants are asked to give their consent or to comment on the interpretation of their interviews and the model based on it, the aim being to improve the credibility and confirmability of the results [100].

\section{Integration and quality assessment}

A triangulation meta-matrix allows second-level analysis by considering all the data simultaneously. Triangulation aims to gather both quantitative and qualitative data (after separate analysis) and integrate them to give a better understanding of the research problem $[104,122]$ via a meta-matrix [105]. This global view allows pattern recognition across data sets, discovery of unexpected relationships or apparent contradictions, and a deeper understanding of the findings. It is a heuristic approach grounded in the phenomenology tradition and is described by Miles \& Huberman [105].

The steps include creating the meta-matrix, transcribing the data (coding the data and noting any reflections that occur during that process), and then looking for common phrases and isolating patterns and processes to be compared with constructs or theory. The matrix and field notes are reviewed at a case analysis meeting, during which a conversation with colleagues helps the researcher grasp meanings despite the large volume of data from different sources [105,107,122]. It is an opportunity to improve the plausibility and confirmability of the findings.

When using a mixed methods design, (Figure 4) it is useful to assess the quality of quantitative and qualitative components separately, but also to have specific quality criteria for the mixed methods components [104]. The criteria proposed by the Mixed Methods Appraisal Tool (MMAT) are used to review the quality of the integration portion of the study [123-125].

Each year, the provisional findings are presented to participating institutions, other researchers, and the scientific or education community, allowing broad, mature consideration of the findings and interpretations and making the final conclusions more trustworthy (stakeholder or member check) [103].

\section{Ethical considerations}

This study was approved by the ethics committee (Comitéd' Éthique hospitalo-facultaire Universitaire de Liège (707)) and assigned reference no. 2017/233.

At each step, participants are given information about the study (aim and process) and about their rights as participants, e.g., confidentiality and the right to refuse or withdraw their consent. More precisely, there are three informed written consent forms: (1) Informed consent by the educational institution; (2) Informed consent to participate in the quantitative part; and (3) Informed consent to participate the qualitative part. Participants are asked to complete the latter two each 
Citation: Dancot J, Pétré B, Detroz P, Gagnayre R, Dardenne N, et al. (2020) Exploring Nursing Student Self-esteem and its Relationship to Clinical Competence Development: Protocol for A Multiphase Convergent Mixed Methods Study. Int J Nurs Clin Pract 7: 324. doi: https://doi.org/10.15344/2394-4978/2020/324

year of participation. The decision to participate or not has no impact on students' educational support or assessment. The data are not used to draw comparisons between identified institutions.

All the data are anonymised, which means that all participants are referred to by code so they cannot be identified. Nominative data are stored in a secure location (in a key-locked cabinet in a key-locked office, computer protected by a security code) for the duration of the study. All nominative data will be destroyed once the research and publication process is over.

Data protection and privacy comply with General Data Protection Regulation (GDPR) principles (UE2016/679) regarding the transparency of data and their use, limited aims, minimising data, limitations on storage duration, data security, and the lawfulness of data processing. Information regarding the collection, use, storage, and destruction of data is available for the participants.

With regard to the interviews, specifically, including potentially sensitive issues, attention is given to kind neutrality. Participants are reminded at the beginning of the interview, and again before sensitive questions, that they have the right not to answer. Participants are asked at the end of the interview how they experienced it and how they feel, so that they can be offered support, if necessary.

\section{Discussion}

Clinical competence is essential for nurses, and self-esteem plays a role in its development and operationalisation. Yet when assessed by students and professionals, clinical competence appears to be only partially, or insufficiently, developed at the end of undergraduate nursing education. Nursing student self-esteem may contribute to the competence development problem, and may be negatively influenced by the educational process.

As illustrated in Table 1, past studies have failed to produce robust, incontrovertible data on self-esteem in nursing students, and so we are unable to draw any conclusions about, or explain, how the phenomenon changes over time. A longitudinal mixed methods study is therefore needed; that study must have a strong theoretical framework, its

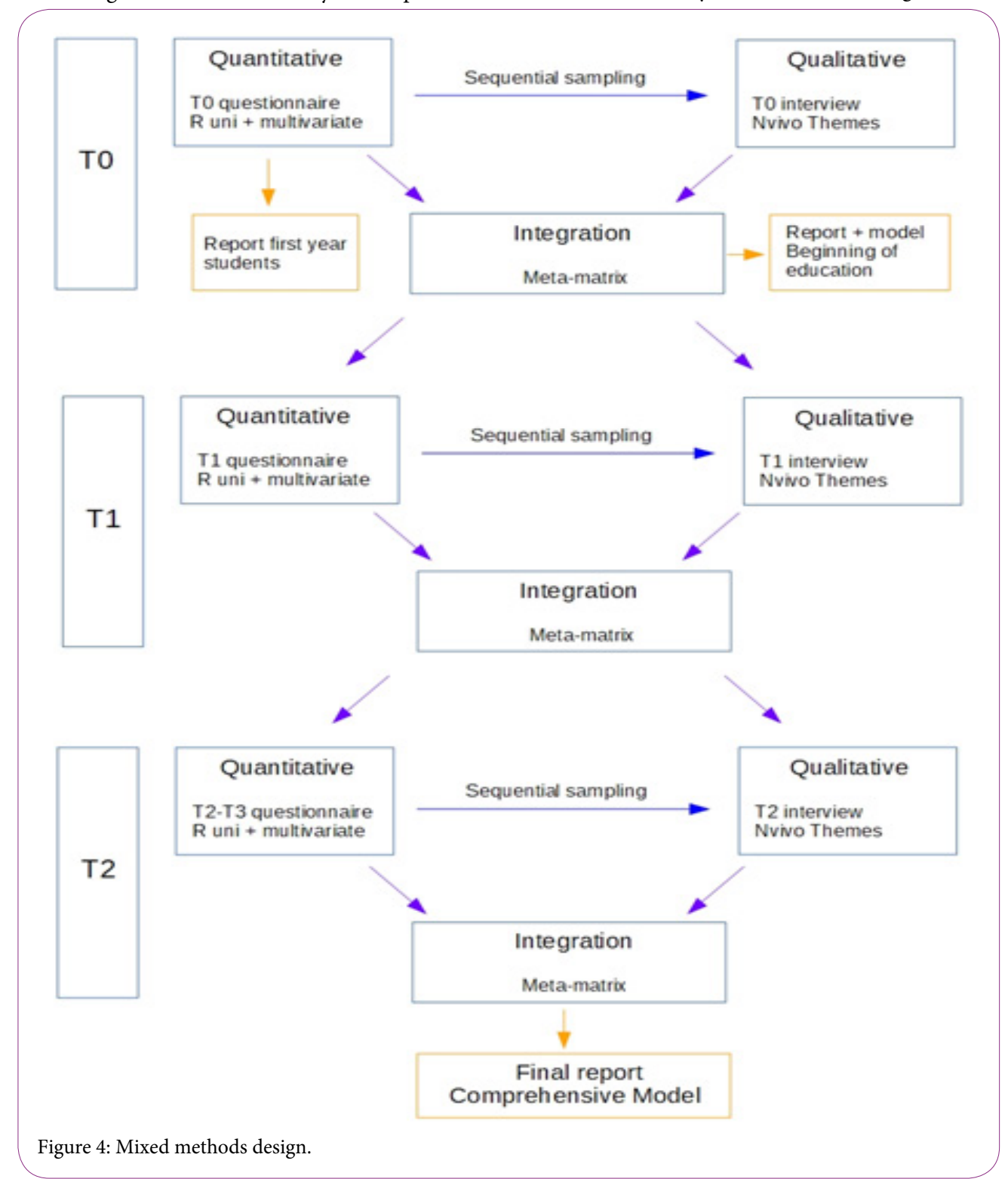


Citation: Dancot J, Pétré B, Detroz P, Gagnayre R, Dardenne N, et al. (2020) Exploring Nursing Student Self-esteem and its Relationship to Clinical Competence Development: Protocol for A Multiphase Convergent Mixed Methods Study. Int J Nurs Clin Pract 7: 324. doi: https://doi.org/10.15344/2394-4978/2020/324

Page 9 of 12

measurement tools and explanations should be consistent with that framework. The aim of this study is to explore the feedback loop between self-esteem and clinical competence development in nursing students, and to understand how undergraduate nursing education impacts that dynamic.

A multiphase convergent design using a mixed methods matrix has been designed to incorporate both the numerical quantification of self-esteem and the qualitative exploration of the dynamic between self-esteem and competence development. The quantitative portion includes measuring the self-esteem level, self-esteem profile (following Mruk's model), and state anxiety; collecting sociodemographic and academic data; and performing correlational statistical analysis. The qualitative part includes exploring educational and external events and their impact on the self-esteem and professional and learning behaviour of students. Quantitative and qualitative data are integrated into a single matrix. The study follows a cohort of nursing students for three years. The mixed methods design and the large cohort size should provide a comprehensive view of the phenomenon. A multiphase convergent design using a mixed methods matrix has been designed to incorporate both the numerical quantification of self-esteem and the qualitative exploration of the dynamic between self-esteem and competence development. The quantitative portion includes measuring the self-esteem level, self-esteem profile (following Mruk's model), and state anxiety; collecting sociodemographic and academic data; and performing correlational statistical analysis. The qualitative part includes exploring educational and external events and their impact on the self-esteem and professional and learning behaviour of students. Quantitative and qualitative data are integrated into a single matrix. The study follows a cohort of nursing students for three years. The mixed methods design and the large cohort size should provide a comprehensive view of the phenomenon.

We consider quantitative [100] and qualitative [100,121] quality criteria when collecting and analysing the respective data types, and mixed methods quality criteria [104,123-125] guide the integration step. The study team includes experts in both qualitative and quantitative methods. The mixed methods design is consistent with the theoretical framework proposed by Mruk [36], and the maximum variation purposive sampling, together with the large sample size, should allow transferability of the findings, whose validity is ensured by the participants (students and institutions) and by a large panel of experts.

We hope that this detailed description of the protocol will allow replication of the study with other populations of nursing students or students in other disciplines.

One practical implication of the study would be that the findings could help educational institutions deal with the issue of nursing student self-esteem by designing activities focused specifically on bolstering self-esteem or by improving activities or methods that impact self-esteem. A second practical implication is that the findings could be used to help these institutions identify "at-risk" students and support them in a way that is consistent with their needs, in terms of self-esteem and competence development.

Future studies might measure the self-esteem of students in different departments to check for homo- or heterogeneity before and during the educational process. The situation of dropouts should be explored. The self-esteem of classroom and clinical nursing instructors could also be explored. Eventually, the impact of activities or steps aimed at improving nursing student self-esteem could be evaluated.
We encountered three main difficulties when designing and implementing the current research protocol. First, the organisation of French-speaking Belgian higher education is not conducive to following a cohort longitudinally. The fact that students have individualised study programmes and do not fit neatly into a specific academic year complicates the logistics of making contact with all of the participants each year. We have chosen to administer the questionnaires during class time to improve the participation rate, and to collect data simultaneously from students in the first two years of study so that we can follow the maximum number of students from one year to the next. The risk of that, however, is that some students in the cohort do not attend the class in question, either because it is not in their individual programme or because they are absent. The result is missing data, which must be addressed using appropriate statistical methods.

The second difficulty is that despite the existence of numerous validated scales, there are still some issues with self-esteem assessment. The Rosenberg Self-Esteem Scale is sometimes used to measure "trait self-esteem" [126] and is not well-suited to the study's theoretical framework, which uses a two-dimensional model of self-esteem. On the other hand, when used to validate the French translation [111], the Self-Liking/Self-Competence Scale (revised version) [38] showed some variability over a three-week interval (during which clinical training occurred). It is difficult to know, based on these elements, whether the observed variation was due to the clinical training and reflected a "self-esteem moment" [36], or if the scale assesses a very transitory state [127]. Comparing RSES-r and SLSC-r findings in the longitudinal study could provide some useful information, as could administering the SLSC-r right before the interview in order to compare the quantitative and qualitative data (a process which could be added to the T1 and T2 interviews).

Lastly, self-esteem and competence development are very complex phenomena with numerous influence and inter influence factors and a feedback loop between them. This complexity, and the large volume of data collected, pose the problem of how to operation alize a metamatrix [105] comprehensive enough to reflect the richness of the phenomena, yet well-structured enough to be readable and useful.

\section{Ethics Approval and Consent to Participate}

This study was approved by the ethics committee (Comitéd' Éthique hospitalo-facultaire Universitaire de Liège (707)) and assigned reference no. 2017/233.

\section{Competing Interests}

The authors declare that they have no competing interests.

\section{Authors' Contributions}

JD is the Principal Investigator, designed the protocol, wrote the manuscript, and leads the study. MG, BP, PD, AFD and RG gave substantial advice during protocol design and description. AFD and ND participated in drafting the statistical analysis plan. All of the authors read and approved the final manuscript.

\section{Acknowledgements}

The Authors want to thank Prof. Monique Rothan-Tondeur (University Paris 13) for her contributions to the design of the study, 
Citation: Dancot J, Pétré B, Detroz P, Gagnayre R, Dardenne N, et al. (2020) Exploring Nursing Student Self-esteem and its Relationship to Clinical Competence Development: Protocol for A Multiphase Convergent Mixed Methods Study. Int J Nurs Clin Pract 7: 324. doi: https://doi.org/10.15344/2394-4978/2020/324

Page 10 of 12

as well as Nina Friedman for her English writing support, and Bernard Voz and Jean-Christophe Servotte (ULiège) for conducting the interviews and handing out the questionnaires, respectively, at the Principal Investigator's institution.

\section{References}

1. Aydin N, Akansel N (2013) Determination of Accuracy of Nursing Diagnoses Used by Nursing Students in their Nursing Care Plans. Int J Caring Sci 6 : 252-257.

2. Bagnasco A, Galaverna L, Aleo G, Grugnetti AM, Rosa F, et al. (2016) Mathematical calculation skills required for drug administration in undergraduate nursing students to ensure patient safety: A descriptive study. Drug calculation skills in nursing students. Nurse Educ Pract 16: 3339.

3. Brown RA, Crookes PA (2016) What are the "necessary" skills for a newly graduating RN? Results of an Australian survey. BMC Nurs 15: 1-8.

4. Brown RA, Crookes PA (2016) What level of competency do experienced nurses expect from a newly graduated registered nurse? Results of an Australian modified Delphi study. BMC Nurs 15: 1-8.

5. Goode CJ, Glassman KS, Ponte PR, Krugman M, Peterman T, et al. (2018) Requiring a nurse residency for newly licensed registered nurses. Nurs Outlook 66: 329-332.

6. Greenwood M, Walkem K, Smith LM, Shearer T, Stirling C, et al. (2014) Postgraduate Nursing Student Knowledge, Attitudes, Skills, and Confidence in Appropriately Referencing Academic Work. J Nurs Educ 53: 447-452.

7. Harvey S, Murphy F, Lake R, Jenkins L, Cavanna A, et al. (2010) Diagnosing the problem: Using a tool to identify pre-registration nursing students mathematical ability. Nurse Educ Pract 10: 119-125.

8. Iacobucci TA, Daly BJ, Lindell D, Griffin MQ (2013) Professional values, self esteem, and ethical confidence of baccalaureate nursing students. Nurs Ethics 20: 479-490.

9. Johnston ANB, Hamill J, Barton MJ, Baldwin S, Percival J, et al. (2015) Student learning styles in anatomy and physiology courses: Meeting the needs of nursing students. Nurse Educ Pract 15: 415-420.

10. Kardong-Edgren S, Campinha-Bacote J (2008) Cultural competency of graduating US Bachelor of Science nursing students. Contemp Nurse 28: $37-44$

11. Kav S, Citak EA, Akman A, Erdemir F (2013) Nursing students' perceptions towards cancer and caring for cancer patients in Turkey. Nurse Educ Pract 13: 4-10.

12. Kuokkanen $L$, Leino-Kilpi $H$, Numminen $\mathrm{O}$, Isoaho $\mathrm{H}$, Flinkman $\mathrm{M}$, et al (2016) Newly graduated nurses' empowerment regarding professional competence and other work-related factors. BMC Nurs 15: 1-8.

13. Leuter C, Petrucci C, Mattei A, Tabassi G, Lancia L, et al. (2013) Ethical difficulties in nursing, educational needs and attitudes about using ethics resources. Nurs Ethics 20: 348-358.

14. Lunney M (2010) Use of Critical Thinking in the Diagnostic Process. Int J Nurs Terminol Classif 21: 82-88

15. McClimens A, Brewster J, Lewis R (2014) Recognising and respecting patients' cultural diversity. Nurs Stand 28: 45-52.

16. Murray BA (2015) Nursing Students' Experiences of Health Care in Swaziland Transformational Processes in Developing Cultural Understanding. J Nurs Educ 54: 65-73.

17. Newton SE, Harris M, Pittiglio L (2013) Constructivist Philosophy and Nursing Student Medication Calculations. Res Theory Nurs Pract 27: 88-94.

18. Orbaek J, Gaard M, Fabricius P, Lefevre RS, Møller T, et al. (2015) Patient safety and technology-driven medication - A qualitative study on how graduate nursing students navigate through complex medication administration. Nurse Educ Pract 15: 203-211.

19. Paans W, Sermeus W, Nieweg R, Van Der Schans C (2010) Determinant of the Accuracy of Nursing Diagnoses: Influence of Ready Knowledge Knowledge Sources, Disposition Toward Critical Thinking, and Reasoning Skills. J Prof Nurs 26: 232-241.

20. Parker WA, Steyn NP, Levitt NS, Lombard CJ (2011) They think they know but do they? Misalignment of perceptions of lifestyle modification knowledge among health professionals. Public Health Nutr 14: 1429-1438.
21. Pohl CJ, Malin S, Kennell L (2014) Reinventing the Home Visit for Undergraduate Nursing Students. J Nurs Educ 53: 696-698.

22. Lewallen LP, DeBrew JK (2012) Successful and Unsuccessful Clinical Nursing Students. J Nurs Educ 51: 389-395

23. Riley D, Smyer T, York N (2012) Cultural Competence of Practicing Nurses Entering an RN-BSN Program. Nurs Educ Perspect 33: 381-385.

24. Røykenes K (2016) "My math and me": Nursing students' previous experiences in learning mathematics. Nurse Educ Pract 16: 1-7.

25. Shepherd J (2013) Messy boundaries: younger students' experiences of nursing young people in hospital. Nurs Child Young People 25: 23-26.

26. Studnicka K, O'Brien K (2016) Where Is the Nursing?: Baccalaureate Nursing Students' Perceptions of Nontraditional Child Health Clinical Placements. J Nurs Educ 55: 349-352.

27. Milisen K, De Busser T, Kayaert A, Abraham I, Dierckx De Casterle B. The evolving professional nursing self-image of students in baccalaureate programs: A cross-sectional survey. Int J Nurs Stud 47: 688-698.

28. Kävelmark Sporrong $S$, Bengt $A$, Hansson MG, Westerholm P, Höglund AT, et al. (2007) Developing Ethical Competence in Health Care Organizations. Nurs Ethics 14: 825-837.

29. Leckasseur K (2009) Mobilisation des savoirs par une pensée critique chez des étudiantes infirmières bachelières en situation de soins. Université Laval.

30. Burns P, Poster EC (2008) Competency Development in New Registered Nurse Graduates: Closing the Gap between Education and Practice. J Contin Educ Nurs 39: 67-73.

31. Guindon MH (2010) Self-Esteem across the Lifespan. Issues and Interventions. Routledge, editor. New-York: Taylor \& Francis.

32. Nader-Grosbois N, Fiasse C (2016) De la perception à l'estime de soi. Concept, évaluation et intervention. Louvain-la-Neuve: De Boeck Supérieur 2016.

33. Randle J (2003) Changes in self-esteem during a 3 year pre-registration diploma in higher education (nursing) programme. Learn Heal Soc Care 2: 51-60.

34. Randle J (2003) Bullying in the nursing profession. J Adolesc 43: 395-401.

35. Shavelson RJ, Hubner JJ, Stanton GC (1976) Self-Concept: Validation of Construct Interpretations. Rev Educ Res 46: 407-441.

36. Mruk CJ (2013) Self-Esteem and Positive Psychology. Research, Theory and Practice. 4th ed. New-York: Springer Publishing Company.

37. Tafarodi RW, Swann WBJ (1995) Self-Liking and Self-Competence as Dimensions of Global Self-Esteem: Initial Validation of a Measure. J Pers Assess 65: 322-342.

38. Tafarodi RW, Swann WBJ (2001) Two-dimensional self-esteem: theory and measurement. Pers Individ Dif 31: 653-673.

39. Rosenberg M (1965) Society and the Adolescent Self-Image. Rahway: Princeton University Press.

40. Bryer J, Peterson-graziose V, Nikolaidou M (2015) Self-esteem and self-efficacy as predictors of attrition in RN-BS completion students: A descriptive correlational study. Teach Learn Nurs 10: 30-34.

41. Unal S (2012) Evaluating the effect of self-awareness and communication techniques on nurses' assertiveness and self-esteem. Contemp Nurse 43: 90-98.

42. Go M (1998) Changes in self-esteem and professional competence in registered nurse graduates of a baccalaureate nursing program: a longitudinal study. University of Maryland College Park.

43. Lees S, Ellis N (1990) The design of a stress-management programme for nursing personnel. J Adv Nurs 15: 946-961.

44. Begley $C M$, White $P(2003)$ Irish nursing students' changing self-esteem and fear of negative evaluation during their preregistration programme. J Adv Nurs 42: 390-401.

45. Farid A, Kaleybar RH, Ghobadi L, Mousavi SR (2017) Prediction of Students' Attitudes toward Euthanasia Using Their Religious Orientation, Self-Esteem and Death Anxiety. Heal Spiritual Med Ethics 4: 2-7.

46. Hallsten L, Rudman A, Gustavsson P (2012) Does Contingent Self-Esteem Increase During Higher Education? Self Identity 11: 223-236

47. Ferreira Furegato AR, Ferreira Santos JL, da Silva EC (2008) Depression among nursing students associated to their self-esteem, health perception and interest in mental health. Rev Lat Am Emfermagem 16: 198-204. 
Citation: Dancot J, Pétré B, Detroz P, Gagnayre R, Dardenne N, et al. (2020) Exploring Nursing Student Self-esteem and its Relationship to Clinical Competence Development: Protocol for A Multiphase Convergent Mixed Methods Study. Int J Nurs Clin Pract 7: 324. doi: https://doi.org/10.15344/2394-4978/2020/324

Page 11 of 12

48. Choi $Y$ (2016) Evaluation of a program on self-esteem and ego-identity for Korean nursing students. Nurs Heal Sci 18: 387-392.

49. El-wahab SDA, Eita LH (2015) Impact of counseling on self-esteem and anxiety levels among nursing students. J Nurs Educ Pract 5: 106-113.

50. Gauthier J, Kjervik D (1982) Sex-Role Identity and Self-Esteem in Female Graduate Nursing Students. Sex Roles 8: 45-55.

51. Gomes Lima BV de B, Pedrosa Trajano FM, Chaves Neto G, Santos Alves $\mathrm{R}$, Alves Farias J, et al. Evaluation of Anxiety and Self-Esteem in Students Concluding the Nursing Graduation Course. J Nursing-Revista Enferm UFPE Line 11: 4326-4333.

52. Megahed MM, Mohammad FA (2014) Effect of cooperative learning on undergraduate nursing students' self-esteem: A quasi- experimental study. J Nurs Educ Pract 4: 1-7.

53. Suliman WA, Halabi J (2007) Critical thinking, self-esteem, and state anxiety of nursing students. Nurse Educ Today 27: 162-168.

54. Burgess GR (1982) The Self-Concept of Undergraduate Nursing Students in Relation to Clinical Performance and Selected Biographical Variables (Part II). Issues Nurs Res.

55. Ellis LS (1980) An Investigation of Nursing Student Self-Concept Levels: A Pilot Survey. Nurs Res 29: 389-390.

56. Gurdogan EP, Uslusoy EC, Kurt S, Yasak K (2016) Comparison of the Self Esteem and Communication Skills at the 1st and Senior Year Nursing Students. Int J Caring Sci 9: 496-502.

57. Ni C, Lo D, Liu X, Yang Q, Ma J, et al. (2012) Chinese female nursing students coping strategies, self-esteem and related factors in different years of school. J Nurs Educ Pract 2: 33-41.

58. Edwards D, Burnard P, Bennett K, Hebden U (2010) A longitudinal study of stress and self-esteem in student nurses. Nurse Educ Today 30: 78-84

59. Hughes LC, Romick P, Sandor MK, Phillips CA, Glaidster J, et al. (2003) Evaluation of an Informal Peer Group Experience on Baccalaureate Nursing Students' Emotional Well-Being and Professional Socialization. J Prof Nurs 19: 38-48.

60. Klug C (1989) Changes in Self-Concept during Baccalaureate Nursing Education. Nurse Educ 14: 7

61. Sobol EG (1978) Self-Actualization and the Baccalaureate Nursing Students Response to Stress. Nurs Res 27: 238-244.

62. Clark CC (2008) Classroom Skills for Nurse Educators. Sudbury: Jones and Bartlett.

63. Burnard P, Hebden U, Edwards D (2001) Self-esteem and student nurses: An account of a descriptive study. Nurs Heal Sci 3: 9-13.

64. Cha NH, Sok SR (2014) Depression, self-esteem and anger expression patterns of Korean nursing students. Int Nurs Rev 61: 109-115.

65. Lopes Chaves EC, Prado Simao T, Siqueira de Oliveira I Prado de Souza I Hollanda Iunes D, et al. (2013) Assessment of nursing students' self-esteem at a university in the South of Minas Gerais (Brazil). Invest Educ Enferm 31 261-269.

66. Hughes O, Wade B, Peters M (1991) The Effects of a Synthesis of Nursing Practice Course on Senior Nursing Students' Self-Concept and Role Perception. J Nurs Educ 30: 69-72.

67. Illhan N, Sukut Ö, Utas Akhan L, Batmaz M (2016) The effect of nurse education on the self-esteem and assertiveness of nursing students: $A$ fouryear longitudinal study. Nurse Educ Today 39: 72-78.

68. Jang HJ, Jeon MK (2017) A Study on Anger Expression Mode of Nursing Students. Res J Pharm Technol.

69. Karagözoglu S, Kahve E, Koç O, Adamisoglu D (2008) Self esteem and assertiveness of final year Turkish university students. Nurse Educ Today 28: 641-649.

70. Lo R (2002) A longitudinal study of perceived level of stress, coping and self-esteem of undergraduate nursing students: an Australian case study. $J$ Adv Nurs 39: 119-126.

71. Ross R, Zeller R, Srisaeng P, Yimmee S, Somchid S, et al. (2005) SelfEsteem among Baccalaureate Nursing Students in Thailand. Int J Nurs Educ Scholarsh 2: 25.

72. Shepherd JM, Brooks KL (1991) Self-Concept among Senior Students in Four Types of Nursing Education Programs. Nurse Educ 16: 8-9.

73. Windsor A (1987) Nursing Students' Perceptions of Clinical Experience. J Nurs Educ 26: 150-154.
74. Zamanzadeh V, Valizadeh L, Gargari RB, Ghahramanian A (2016) Nursing Students' Understanding of the Concept of Self -Esteem: a Qualitative Study. J Caring Sci 5: 33-41.

75. Randle J (2001) The effect of a 3-year pre-registration training course on students' self-esteem. J Clin Nurs 10: 293-300.

76. Kim M, Park SY (2011) Factors Affecting the Self-directed Learning of Students at Clinical Practice Course for Advanced Practice Nurse. Asian Nurs Res 5: 48-59.

77. Valizadeh L, Zamanzadeh V, Badri Gargari R, Ghahramanian A, Jabbarzadeh Tabrizi F, et al. (2016) Pressure and protective factors influencing nursing students' self-esteem: A content analysis study. Nurse Educ Today 36: 468472.

78. Lin YR, Shiah I, Chang YC, Lai TJ, Wang KY, et al. (2004) Evaluation of an assertiveness training program on nursing and medical students assertiveness, self-esteem, and interpersonal communication satisfaction. Nurse Educ Today 24: 656-665.

79. Gammon J, Morgan-Samuel H (2005) A study to ascertain the effect of structured student tutorial support on student stress, self-esteem and coping. Nurse Educ Pract 5: 161-171.

80. Karaca A, Yildirim N, Cangur S, Acikgoz F, Akkus D, et al. (2019) Relationship between mental health of nursing students and coping, self- esteem and social support. Nurse Educ Today 76: 44-50.

81. Ni C, Liu X, Hua Q, Lv A, Wang B, et al. (2010) Relationship between coping, self-esteem, individual factors and mental health among Chinese nursing students: A matched case-control study. Nurse Educ Today 30: 338-343.

82. Yildirim N, Karaca A, Cangur S, Acikgoz F, Akkus D (2017) The relationship between educational stress, stress coping, self-esteem, social support, and health status among nursing students in Turkey: A structural equation modeling approach. Nurse Educ Today 48: 33-39.

83. Brajsa-zganec A, Lipovcan LK, Ivanovic D, Larsen ZP (2017) Well-Being of Nursing Students: Role of Affect Regulation, Self- Esteem, Family Cohesion and Social Support. Open Public Health J 10: 69-79.

84. Sakellari E, Psychogiou M, Georgiou A, Papanidi M, Vlachou V, et al. (2017) Exploring Religiosity, Self-Esteem, Stress, and Depression Among Students of a Cypriot University. J Relig Health 57: 136-145.

85. Papazisis G, Nicolaou P, Tsiga E, Christoforou T, Sapountzi-Krepia D, et al (2014) Religious and spiritual beliefs, self-esteem, anxiety, and depression among nursing students. Nurs Heal Sci 16: 232-238.

86. Whelan M (1996) Self-esteem and competitiveness among nurse practicioner students. Columbia University Teachers College.

87. Aloba O, Olabisi O, Ajao O, Aloba T (2017) The Beck Hopelessness Scale: Factor structure, validity, and reliability in a non-clinical sample of student nurses in South-western Nigeria. J Behav Heal 6: 58-65.

88. Yoon HS, Kim GH, Kim J (2011) Effectiveness of an Interpersonal Relationship Program on Interpersonal Relationships, Self-esteem, and Depression in Nursing Students. J Korean Acad Nurs 41: 805-813.

89. Augusto Landa JM, López-zafra E, Aguilar-Luzón M del C, Fe Salguero De Ugarte M (2009) Predictive validity of Perceived Emotional Intelligence on nursing students' self-concept. Nurse Educ Today 29: 801-808.

90. Lewis J, Bentley C, Sawyer A (1980) The Relationship Between Selected Personality Traits and Self-Esteem Among Female Nursing Students. Educ Psychol Meas 40: 259-260.

91. McLaughlin K, Moutray M, Muldoon OT (2008) The role of personality and self-efficacy in the selection and retention of successful nursing students: $A$ longitudinal study. J Adv Nurs 61: 211-221.

92. Amr M, El-Gilany AH, El-Moafee H, Salama L, Jimenez C, et al. (2011) Stress among Mansoura (Egypt) baccalaureate nursing students. Pan Afr Med J 8: 26.

93. Crary P (2013) Beliefs, behaviors, and health of undergraduate nursing students. Holist Nurs Pract 27: 74-88.

94. Aeamla-Or N (2015) The Effect of Mindfulness-based Stress Reduction on Stress, Depression, Self-esteem and Mindfulness in Thai Nursing Students: A Randomised Controlled Trial. University of Newcastle.

95. Taylor B (2001) The effects of Healing Touch on the coping ability, self esteem and general health of undergraduate nursing students. Complement Ther Nurs Midwifery 7: 34-42

96. Famose JP, Bertsch J (2009) L'estime de soi: une controverse éducative. Paris: PUF. 
Citation: Dancot J, Pétré B, Detroz P, Gagnayre R, Dardenne N, et al. (2020) Exploring Nursing Student Self-esteem and its Relationship to Clinical Competence Development: Protocol for A Multiphase Convergent Mixed Methods Study. Int J Nurs Clin Pract 7: 324. doi: https://doi.org/10.15344/2394-4978/2020/324

Page 12 of 12

97. Mruk CJ (2013) Defining Self-Esteem as a Relationship between Competence and Worthiness: How a Two-Factor Approach Integrates the Cognitive and Affective Dimensions of Self-Esteem. Polish Psychol Bull 44: 157-164.

98. Mruk CJ (2010) Integrated Description: A Qualitative Method for an Evidence-Based World. Humanist Psychol 38: 305-316.

99. Bosson JK, Swann WBJ, Pennebaker JW (2000) Stalking the Perfect Measure of Implicit Self-Esteem: The Blind Men and the Elephant Revisited? J Pers Soc Psychol 79: 631-643.

100. Fortin MF, Gagnon J (2016) Fondements et étapes du processus de recherche: Méthodes quantitatives et qualitatives. 3rd ed. Montréal: Chenelière Education.

101. Morgan DL (2014) Pragmatism as a Paradigm for Social Research. Qual Inq 20: $1045-1053$

102. Johnson RB, Onwuegbuzie AJ (2004) Mixed Methods Research: A Research Paradigm Whose Time Has Come. Am Educ Res Assoc 33: 14-26.

103. Thomas DR (2006) A General Inductive Approach for Analyzing Qualitative Evaluation Data. Am J Eval 27: 237-246.

104. Pluye P, Hong QN (2014) Combining the Power of Stories and the Power of Numbers: Mixed Methods Research and Mixed Studies Reviews. Annu Rev Public Health 35: 29-45.

105. Wendler MC (2001) Triangulation using a meta-matrix. J Adv Nurs 35: 521 525

106. Meissner HI, Creswell JW, Klassen AC, Clark VLP, Smith KC, et al. (2011) Best Practices for Mixed Methods Research in the Health Sciences.

107. O'Cathain A, Murphy E, Nicholl J (2010) Three Techniques for Integrating Data in Mixed Methods Studies. BMJ 341: c4587.

108. Creswell JW (2009) Mixed Methods Procedures. In: Research Design. 3rd ed Thousand Oaks: SAGE.

109. Moran-Ellis J, Alexander VD, Cronin A, Dickinson M, Fielding J, et al. (2006) Triangulation and integration: processes, claims and implication. Qual Res 6. $45-59$

110. Gebauer JE, Riketta M, Broemer P, Maio GR (2008) How much do you like your name?" An implicit measure of global self-esteem. J Exp Soc Psychol 44: $1346-1354$

111. Hébert R, Bravo $G$, Voyer $L$ (1994) La traduction d'instruments de mesure pour la recherche gérontologique en langue française: critères métrologiques et inventaire. La Rev Can du Vieil 13: 392-406.

112. Corwyn RF (2000) The Factor Structure of Global Self-Esteem among Adolescents and Adults. J Res Pers 34: 357-379.

113. Gana K, Alaphilippe D, Bailly N (2005) Factorial Structure of the French Version of the Rosenberg Self-Esteem Scale Among the Elderly. Int J Test 5: $169-176$

114. Marsh HW (1996) Positive and Negative Global Self-Esteem: A Substantively Meaningful Distinction or Artifactors? J Pers Soc Psychol 70: 810-819.

115. Tomas JM, Amparo O (1999) Rosenberg's self-esteem scale: Two factors or method effects. Struct Equ Model A Multidiscip J 6: 84-98.

116. Vallières EF, Vallerand RJ (1990) Traduction et validation canadiennefrançaise de l'échelle de l'estime de soi de Rosenberg. Int J Psychol 25 : 305-316

117. Langevin $V$, Boini $S$, François $M$, Riou $A$ (2012) Inventaire d'anxiété État-Trait Forme $Y$ [State-Trait Anxiety Inventory (STAI-Y)]. Références en Santé au Trav 131: 161-164

118. Ryan GW, Bernard HR (2003) Techniques to Identify Themes. Field methods 15: 85-109.

119. Morse JM (2015) "Data Were Saturated ...." Qual Health Res 25: 587-588.

120. Morse JM (1995) The Significance of Saturation. Qual Health Res 5: 147-149.

121. Malterud K (2001) Qualitative research: standards, challenges, and guidelines. Lancet 358: 483-488.

122. Creswell JW, Fetters MD, Ivankova NV (2004) Designing A Mixed Methods Study In Primary Care. Ann Fam Med 2: 7-12.

123. Souto RQ, Khanassov V, Hong QN, Bush PL, Vedel I, et al. (2015) Systematic mixed studies reviews: Updating results on the reliability and efficiency of the mixed methods appraisal tool. Int J Nurs Stud 52: 500-501.
124. Pace R, Pluye P, Bartlett G, Macaulay AC, Salsberg J, et al. (2012) Testing the reliability and efficiency of the pilot Mixed Methods Appraisal Tool (MMAT) for systematic mixed studies review. Int J Nurs Stud 49: 47-53.

125. Pluye P, Gagnon M, Griffiths F, Johnson-Lafleur J (2009) A scoring system for appraising mixed methods research, and concomitantly appraising qualitative, quantitative and mixed methods primary studies in Mixed Studies Reviews. Int J Nurs Stud 46: 529-546.

126. van der Miesen M (2015) The Role of Self-Esteem in Social Feedback: An fMRI study. Amsterdam.

127. Heatherton TE, Polivy J (1991) Development and Validation of a Scale for Measuring State Self-Esteem. J Pers Soc Psychol 60: 895-910. 